diversos, mas igualmente importantes nos estudos da ruralidade. O tema da juventude aparece com um estudo empírico no sul de Minas Gerais, que enxerga a sucessão familiar enquanto um processo de transmissão do comando da propriedade, no qual o risco de dissolução é alto pela falta de planejamento familiar. $O$ artigo põe à tona, também, os tabus religiosos, no sentido de que a sucessão é evitada pelas famílias em razão de sua associação com a morte dos pais. Em outro artigo, histórias de vida de familias rurais são retratadas em um exercício metodológico que reconstrói a militância dos pais, alertando para dimensões poucos visiveis na luta pela terra. Encerrando o volume, e na contramão da bancada ruralista, um artigo apresenta a atuação da bancada do PT como protagonista da reforma agrária no Congresso Nacional, situação que certamente não corre por mares tranquilos.

Este volume de Retratos não quer alimentar consensos, mas sim estimular debates, analisar casos concretos, produzir críticas e a continuidade das nossas utopias. Boa leitura!

Os Editores

\section{COMÉRCIO TRADICIONAL DE ALIMENTOS: AVANÇO NA CONTRACORRENTE}

Luísa Corrêa Leda Newton Narciso Gomes $\mathrm{Jr}^{2}$

Resumo: O sistema de abastecimento alimentar no Brasil experimentou profundas modificações nas últimas décadas em especial a partir da intensificação da urbanização na década de 1960. A contínua concentração do setor de varejo vem, desde então, modificando a forma de aquisição de alimentos nas cidades, a organização das cadeias de suprimento e o padrão alimentar da população, caracterizada por um processo de homogeneização. Contudo, ao lado da expansão das grandes redes de supermercados resistem formas tradicionais de comercialização de alimentos, como feiras, mercados municipais e pequenos equipamentos comerciais familiares distribuídos pelas cidades. Isto posto, o presente artigo tentou captar de forma panorâmica essas modificações e apontar para uma outra perspectiva e abordagem que lide com a condição de acesso e com o formato de organização do sistema de abastecimento alimentar no Brasil no atual contexto. Tentou-se especialmente compreender como a resistência do sistema tradicional de comercialização e seu arranjo de organização podem significar um freio ao atual processo de concentração do varejo de alimentos e de transição alimentar sofrido pela população.

Palavras-chave: Sistema de abastecimento alimentar; Mercado tradicional de alimentos; Varejo alimentar. de Pesquisa sobre Abastecimento Alimentar e Comida - CNPQ/MADER/UnB; e mail luisa.ternera@gmail.com ${ }^{2}$ Economista, Professor Adjunto da UnB, membro permanente do Programa de Pós Graduação em meio Ambiente e Desenvolvimento Rural - MADER/FUP/UnB, coordenador do Núcleo de Estudos sobre Abastecimento Alimentar e Comida CNPQ/MADER/UnB, pesquisador do Núcleo de Estudos Agrários - NEAGRI/CEAM/UnB 
Abstract:The food supply system in Brazil has undergone profound changes in the last decades, especially from the intensification of urbanization in the 1960s. The continuous concentration of the retail sector has since modified the way food is acquired in the cities, the organization of the supply chains and the food standard of the population, characterized by a process of homogenization. However, alongside the expansion of the large supermarket chains, traditional forms of food marketing, such as fairs, municipal markets and small family-run commercial equipment distributed by the cities, resist. This article attempts to capture these changes in a panoramic way and to point out another perspective and approach that deals with the condition of access and with the organizational format of the food supply system in Brazil in the current context. It was especially tried to understand how the resistance of the traditional marketing system and its arrangement of organization can be a brake to the current process of concentration of food retail and food transition suffered by the population

Keywords: Food supply system; Traditional food market; Food retails system.

\section{Introdução}

O abastecimento alimentar de grandes e médias cidades brasileiras, desde que o supermercado em meados dos anos 1960 consolidou-se como opção moderna, prática e barata para gastos com alimentação e produtos de higiene e limpeza, viu o seu setor convencional caracterizado pelos equipamentos tais como feiras - livres, mercados municipais, armazéns, açougues, mercearias e quitandas perder importância a ponto de literalmente terem sido extintos inúmeros tipos de varejo de alimentos.

Entretanto, as feiras livres e os mercados municipais resistiram ao efeito "arrasa quarteirão" da era dos supermercados e seguem operando até os dias de hoje ora com mais ora com menos pujança, mas, ainda assim, sobrevivendo e atraindo para seus espaços uma clientela fiel que não se incomoda com aglomerações e com a aparente desorganização desse tipo de comércio. Persiste e resiste, ainda, uma cumplicidade entre compradores e vendedores que passa de geração para geração tanto de um lado quanto de outro dos tabuleiros que cumprem o papel de balcões.

No ensaio que apresentamos a seguir buscamos discutir o papel e o potencial desses equipamentos de varejo, feiras livres e mercados municipais.

Nossa abordagem foi dividida em duas partes conectadas entre si. Na primeira nos dedicamos rapidamente a uma discussão teórica sobre os
(BELIK, 2001).

Nos anos iniciais da década de 1970, no ápice do surto de industrialização iniciado em 1968 e com taxa de desemprego aberto próxima de zero, pelo menos $60 \%$ da população nacional apresentava algum grau de desnutrição decorrente da assimetria entre a renda disponível nas mãos da maioria da população e os preços praticados pelo mercado para os itens da cesta salário (MULLER, 1986). A carestia, como ficou conhecido esse período na história política do país, forneceu o combustível para que ressurgissem movimentos sociais sufocados pelo governo militar, reivindicando melhores condições de vida para o povo (SANTAGADA, 1990).

A conjuntura tensa foi traduzida pelo governo como potencialmente perigosa para o regime e seus compromissos com a acumulação de capitais e interesses associados a isso. No diagnóstico realizado pelos técnicos de planejamento e agricultura o problema da carestia foi relacionado não com as causas estruturais do modelo de desenvolvimento econômico notadamente dependente do financiamento externo, inflacionário, concentrador de renda e excludente, mas, com ineficiências do sistema de abastecimento assentado no arcaísmo de equipamentos de varejo e atacado responsáveis pela especulação com preços e fragmentações da oferta. Tal diagnóstico, relata Belik (2001), iria resultar em uma nova política voltada para o que se anunciou como modernização do abastecimento, centrada na criação das CEASA's e no apoio e incentivo à implantação e expansão do autosserviço no Brasil.

Ao lado da criação e implantação de centrais de abastecimento públicas (as CEASAs) nas capitais e principais núcleos urbanos do país, com vistas a organizar o atacado de hortifrutigranjeiros, a política de modernização do abastecimento passou a incentivar, também, a especialização dos comerciantes e as economias de escala no sistema de comercialização (BELIK, 2001).

O modelo de varejo que orientou a política se baseou essencialmente no autosserviço ${ }^{4}$ norte-americano que, diferentemente do comércio tradicional, operava em larga escala e utilizava novas tecnologias de estoque e armazenagem as quais possibilitavam acentuado barateamento dos preços de secos e molhados. A partir de então, os supermercados converteram-se em

${ }^{4} \mathrm{~A}$ ideia do autosserviço foi patenteada em 1917 nos Estados Unidos juntamente com a criação dos check-outs e da automação da compra cujo foco foi a disseminação de lojas especializadas em produtos industrializados. Trata-se de uma inovação logística orientada para a expansão do consumo de massa e para a exposição de um número gigante de mercadorias. Os supermercados são, portanto, uma criação intimamente relacionada à expansão das firmas alimentícias, ou seja, da comida industrializada (COCKRALL-KING, 2012). 
supermercados e seus impactos positivos e negativos tanto no abastecimento alimentar quanto na formação de novos hábitos de compras e consumo.

$\mathrm{Na}$ segunda seção discutimos o setor tradicional de comercialização varejista de alimentos para encerrarmos essa discussão destacando as vantagens que identificamos na preservação e estímulo aos sistemas tradicionais de comercialização. Os argumentos foram arranjados de sorte a defender a ideia de que o sistema convencional de comercialização varejista de alimentos representa uma possibilidade efetiva de melhorar, nas cidades, as condições de acesso da população a uma alimentação diversificada e segura.

\section{Traços gerais do sistema alimentar brasileiro recente}

O sistema de abastecimento alimentar no Brasil experimentou profundas modificações nas últimas décadas, modificações estas que sucederam o surto de urbanização tardio simultâneo às transformações no campo que, sob a perspectiva da modernização conservadora, reforçou a concentração da terra ao mesmo tempo em que expulsou para a cidade milhões de pessoas a partir dos anos finais de 1960 .

A atuação de grupos "oligopsônicos ${ }^{3}$ " que controlaram e geraram especulação em torno do comércio de alimentos tradicional (DE MELLO, 1982), dominante até os anos 1970, sempre se valeram das dificuldades técnicas, financeiras e de logística que faziam com que a produção agrícola voltada para o abastecimento interno de alimentos fosse notadamente inconstante e fragmentada (PAIVA, 1965). Com a opção pela monocultura de poucas espécies voltadas para o mercado externo, implementada a partir da versão brasileira da Revolução Verde, o que antes já era problemático piorou, na medida em que as culturas alimentares tradicionais foram deslocadas espacialmente em relação aos centros de consumo urbano que inchavam com os contingentes populacionais expulsos do campo sem que fossem resolvidos os gargalos de circulação e distribuição desses alimentos (DA SILVA, 1972).

A instabilidade da oferta, a especulação recorrente e a escalada de preços dos gêneros básicos converteram-se rapidamente em um problema de Estado, uma vez que seu potencial explosivo representava uma ameaça real aos interesses representados no governo brasileiro pelo autoritarismo dos militares e civis que comandavam a nação desde o golpe de 1964 ${ }^{3}$ Diz respeito à uma estrutura de mercado caracterizada por haver um número pequeno de compradores. ícone da modernidade nas cidades, ofertando a preços muito baixos quando comparados com o comércio tradicional, uma ampla gama de produtos industrializados de alimentação, higiene e limpeza, utilidades domésticas, roupas dentre muitos outros, alcançando todas as faixas de renda. Entre 1969 e 1970, os supermercados subiram sua participação no varejo de alimentos de $1 \%$ para $13 \%$ (SUPERMERCADO MODERNO, 2010).

Uma série de ondas de disseminação de grandes redes de varejo ocorreu no Brasil desde então, primeiramente estruturadas sobre o capital nacional e, mais recentemente, na expansão das grandes redes transnacionais de varejo, especialmente por fusões e aquisições de redes nacionais (BELIK, 2001). Cresceu igualmente a fusão de atividades de distribuição e comercialização, estimulando cada vez mais uma organização especializada e verticalizada ao longo da cadeia de abastecimento e um sistema de abastecimento altamente concentrado.

No Brasil, a primeira onda de se deu a partir de 1980 e foi marcada pela aquisição, por parte das grandes redes de supermercados, de lojas independentes e cadeias locais (BELIK, 2001). A década seguinte foi marcada pelo ingresso forte das redes internacionais que rapidamente assumiram o controle das grandes redes de capital nacional: entre 1976 e 1998 as lojas de supermercado saltaram de 997 para 51.500 lojas no Brasil, passando, na década de 1990, a deter 86,3\% das vendas de varejo (SILVEIRA; SANTOS, 2001).

Em 2000, as cinco maiores redes de supermercados no Brasil ${ }^{5}$ controlavam 41\% do mercado, subindo para 53\% em 2013 (ABRAS, 2014). Em 2015 o setor supermercadista brasileiro faturou mais de R\$ 315 bilhões, um crescimento de 7,1\% em relação a 2014, e o faturamento das 20 maiores empresas correspondeu a cerca de $64 \%$ do faturamento total do setor, sendo essa proporção maior do que 50\% para as cinco maiores, que possuem mais de 3.200 lojas no país (ABRAS, 2016).

Ao longo desse processo, as grandes redes de varejo passaram a ampliar seu controle de mercado não apenas como varejistas, mas, como atores dominantes na organização geral do abastecimento. Os supermercados, na condição de monopólios incentivados pelo Estado, inseriram novas tecnologias e lógicas de produção e distribuição que acirraram a competição no setor. A fusão de atividades de distribuição e comercialização cresceu ao lado da progressiva introdução de hortifrutigranjeiros na pauta de

\footnotetext{
${ }^{5}$ As cinco maiores redes de supermercados do Brasil: Pão de Açúcar, Carrefour, Walmart, Ceconsud e Záfari
} 
comercialização dos supermercados e as grandes redes passaram a exercer cada vez mais domínio sob a organização do próprio atacado de produtos in natura, modificando o arranjo do sistema abastecimento de hortifrutigranjeiros (REARDON; BERDEGUÉ, 2006).

Desenvolveu-se progressivamente um sistema de abastecimento paralelo composto por serviços especializados de aquisição em zonas de produção (Plataformas Privadas) e que se distanciou das CEASAs e suas estruturas de distribuição. A expansão das plataformas privadas de distribuição de produtos frescos, denota que os supermercados têm avançado no sentido de firmar contratos diretamente tanto com a indústria alimentícia como com os produtores rurais, privilegiando os segmentos mais capitalizados e capazes de operar com a escala requerida pelo varejo moderno, inviabilizando atividades das pequenas unidades de produção agrícola ou industriais locais e regionais. (REARDON; BERDEGUÉ, 2002; BELIK; CHAIM, 1999).

A forma como se verticalizam e se formam as cadeias especializadas varia de produto para produto e estão bastante relacionadas à expansão da produção de frutas, legumes e verduras voltados à exportação ${ }^{6}$. Essa dinâmica de dominância vertical depende, também, da intensidade com a qual a transformação do sistema de varejo foi - e é - capaz de reconfigurar o mercado atacadista tradicional e de como essa estrutura afeta a cadeia de abastecimento para trás da porteira. É comum os circuitos dominantes e oligopolizados coexistirem com os sistemas tradicionais e "nacionais" de abastecimento (REARDON; BERDEGUÉ, 2006).

Para Belik e Cunha (2012), a dinâmica do comércio atacadista não é mais determinada e impulsionada no âmbito das centrais de abastecimento, mas sim em outros circuitos da grande distribuição. Os autores afirmam haver, de modo geral, uma dinâmica de crescimento de "fora para dentro" nas centrais públicas, o que limita que esses equipamentos exerçam papéis importantes de planejamento do abastecimento.

A concentração da produção em menores espaços, corolário da

\footnotetext{
${ }^{6}$ Alguns exemplos são a produção de laranja em São Paulo, controlada por um pequeno grupo de exportadores de seu suco que controlam igualmente as condições de distribuição e abastecimento da fruta no país. Da mesma forma, a produção de melões no Ceará, cujos principais destinos são Holanda, Alemanha, Inglaterra, França, Espanha e Estados (Ceasa, Ceará) e a produção de uva no Vale do São Francisco, região que entre a década de 1970 e 1980 se tornou produtora de alimentos básicos e posteriormente consolidou-se como grande produtora (14\% 2009). D 1970, a brit 2006) mercado internacional de frutas e vegetais cresceu em torno de 30\% entre 1990 e 2005 (DIOP, JAFFE, 2005).
}

especialização, e em locais mais distantes dos centros consumidores, implica em maiores custos com transporte, desperdícios, e maior dependência de combustível fóssil para a realização da distribuição. Além de uma parte considerável dos alimentos viajarem uma longa distância, abrem-se amplas brechas para especulação: além do distanciamento, os preços dos mais importantes produtos da cesta de consumo não são mais formados dentro das centrais públicas, pois são os grandes "reis dos produtos" que formam os preços dos principais itens de consumo alimentar diário (BELIK; CUNHA, 2012).

No que diz respeito à diversidade produtiva, esta tende não só a diminuir como a se distanciar das condições ecológicas locais, pois os agricultores abandonam explorações mais adequadas às condições naturais no intuito de se adequar às demandas das grandes cadeias. "[...] é comum o agricultor optar pela exploração de um cultivo comercial em virtude das exigências do mercado e abandonar aquelas variedades já adaptadas ao meio ambiente local" (MACHADO et al. 2008, p. 35) e passar a produzir para um mercado distante qualquer. Isso acaba por gerar ainda maior vulnerabilidade dos produtores, que, para produzir espécies não nativas, passam a depender ainda mais do mercado de insumos e de financiamento para tal.

Há, aqui, um elemento fundamental que sustenta e faz parte desse processo amplo de transformações: a modificação dos hábitos alimentares da população. Se levarmos em consideração que a população urbana cresceu de $56 \%$ para $81 \%$ entre as décadas de 1970 e 2000 (IBGE, 2007), vê-se que o setor supermercadista abocanhou grande parte do mercado de alimentos desde então. Em outras palavras, as modificações sofridas pela organização do abastecimento alimentar estão diretamente relacionadas ao intenso processo de transição alimentar presente na vida da população brasileira nas últimas décadas.

Nas primeiras décadas do século XXI, a obesidade e o sobrepeso associados ao consumo inadequado de alimentos ou em outros termos, relacionados com a ingestão excessiva de alimentos processados onde dominam excessos de gordura, sódio e açúcar em detrimento do equilíbrio requerido para que um alimento seja considerado saudável e seguro, converteram-se em epidemia. $\mathrm{O}$ avanço de doenças crônicas não transmissíveis (DCNT) ${ }^{7}$ associadas à má

${ }^{7}$ As mais comuns são diabetes, hipertensão, problemas coronários e de circulação, câncer e colesterol alto. Essas doenças constituem, hoje, o problema de saúde de maior magnitude no Brasil, sendo responsáveis por mais de $70 \%$ das causas de mortes (Pesquisa Nacional de Saúde, IBGE, 2013). Hoje, quase $40 \%$ dos brasileiros adultos $70 \%$ das causas de mortes (Pesquisa Nacional de Saúde, IBGE, 2013). Hoje, quase $40 \%$ dos brasileiros adultos
apresentam pelo menos um tipo de DNCT (Ibid). A obesidade é um dos principais efeitos da transição alimentar e está diretamente associada à maior frequência dessas doenças. 
qualidade da alimentação predominante nos hábitos alimentares de mais da metade da população brasileira é o sinal mais evidente do processo de substituição dos alimentos tradicionais por uma dieta fundada em comida artificializada.

A Pesquisa de Orçamentos Familiares (POF; 2009) do Instituto Brasileiro de Geografia e Estatística (IBGE) explicita as dimensões dessas transformações: no Brasil, em 1980, os produtos in natura participavam com $44 \%$ no consumo alimentar e os alimentos industrializados contribuíam com 56\% desse consumo. A partir da década de 1990 essas proporções se modificaram para $30 \%$ e $70 \%$, respectivamente, chegando, em 2008 , a uma relação de $15 \%$ para consumo de alimentos in natura contra $85 \%$ de alimentos industrializados.

Houve o aumento no consumo de alimentos preparados de 1,7 kg anuais per capita para 5,4 kg entre 1987 e 2003 (POF, 2009). A comparação, feita pelo IBGE, entre os dados da Pesquisa de Orçamentos Familiares, de 2002/2003 e 2008/2009, mostra que continua a crescer o consumo de produtos industrializados enquanto o consumo de arroz e feijão, apresenta viés de baixa, de recuo. Entre 1975 e 2009, o arroz polido apresentou uma redução de $60 \%$ na quantidade anual per capita adquirida para consumo no domicílio, enquanto a aquisição de feijão reduziu em $49 \%$. O aumento no consumo de frutas é pequeno e há uma estagnação observada quanto às verduras, legumes e hortaliças.

Enquanto nas cidades as grandes redes expandem seu poder de mercado e tornam cada vez mais monótona e padronizada a aquisição e consumo de alimentos, para trás da cadeia a agricultura camponesa perde fôlego e diversidade. O controle cada vez maior sobre a organização e distribuição da produção torna a replicação de lojas das grandes redes um fenômeno cotidiano, concentrando o acesso aos alimentos em zonas lucrativas e ampliando a privação do acesso em locais de menor faixa de renda (CUMMINS, 2014). Essa dinâmica tem endossado debates diversos em torno fenômeno do food deserts (desertos alimentares), que aponta para o escasso acesso a alimentos saudáveis ou frescos nas cidades, especialmente onde vivem as pessoas com rendas menores, trabalhadores em geral (BEAULAC et al., 2009).

\section{Resistências: o sistema convencional de varejo na contracorrente}

Nessa perspectiva e considerando o cenário acima delineado, diversos debates têm se orientado para a reflexão em torno de novos arranjos que se contraponham, em alguma medida, às dimensões nocivas de concentração do mercado de alimentos. Uma visão integrada acerca do abastecimento, nessa perspectiva, aliaria o desenvolvimento da agricultura local ou regional - ou mesmo nacional - ao abastecimento interno da população. É nesse sentido que algumas abordagens frisam a importância de repensar a alimentação no interior do planejamento do sistema de provisão de alimentos.

Morgan (2009) denomina essa abordagem de food planingmovement, que vê dimensões como saúde pública, justiça social e integridade ecológica como cruciais para o planejamento de um novo arranjo do sistema de abastecimento. Nessa perspectiva, por exemplo, o rearranjo dos sistemas de abastecimento seria uma importante forma de reverter a lógica de remediar os problemas de saúde pela medicina em prol da construção de um modelo que abarque, em seu interior, a promoção da saúde e o exercício da cidadania em torno da alimentação.

Similarmente, Lang (2009) qualifica essa perspectiva de paradigma da saúde pública ecológica - ecological public health paradigm -, que dá ênfase às formas que o cotidiano e as condições de vida dos sujeitos, como mobilidade urbana e lazer, determinam as dimensões da saúde e da alimentação e viver-versa. Steel (2013), por sua vez, faz um longo debate acerca da formação dos desertos alimentares e sobre a invisibilidade da questão alimentar no planejamento público do espaço urbano, retomando a importância das diversas dimensões da comida no âmbito da convivência social, especialmente no que diz respeito à forma de aquisição dos alimentos.

Alguns exemplos práticos de políticas também ilustram essa preocupação. Nos Estados Unidos, essa perspectiva inspirou a política Philadelphia Healthy Corner Store Network, cujo objetivo é a melhora do acesso a alimentos frescos e de qualidade na cidade, assim como a preservação de práticas alimentares tradicionais. O objetivo é a inserção de alimentos frescos e produzidos localmente em cerca de 600 equipamentos comerciais de pequeno porte, chamados de lojas de esquinas, com até um checkout e com distância de 2000 pés dos moradores do bairro (THE FOOD TRUST, 2014).

Outro exemplo que alia a alimentação tradicional à capilaridade do sistema de abastecimento ocorre na cidade de Barcelona, Espanha, onde desde a década de 1980 o governo local - mediante o Plano Especial de Equipamento Comercial Alimentício de Barcelona - proibiu a comercialização de frutas, 
legumes e verduras pelos supermercados no mercado de rua - ou vizinhança -, como forma de preservar os mercados municipais da cidade - ou seja, o sistema tradicional de comercialização - como pontos de abastecimento ${ }^{8}$.

Outra via possível é a criação, pelo poder público, de mercados regionais de alimentos. Tal como são os foodsheds ${ }^{9}$ ou food hubs, desenhado pelo Departamento de Agricultura dos Estados Unidos. O foco desse modelo é uma análise geográfica ou uma estimação da capacidade regional de fornecimento alimentar para determinada aglomeração urbana. $\mathrm{O}$ objetivo é incentivar a criação de estruturas que permitam oferecer facilidades aos pequenos produtores para que acessem coletivamente serviços desde a reunião da produção à comercialização (BARHAM et al., 2011) ${ }^{10}$.

Os food hubs visam modos de aumentar o acesso a alimentos saudáveis e locais em suas comunidades, especialmente em bairros mais pobres com presença de desertos alimentares, onde as opções de aquisição de alimentos frescos como frutas e verduras são limitadas (BARHAM et al., 2011). Esse exemplo se aproxima da abordagem desenvolvida por Wiskerke (2009), que frisa a diminuição de intermediações ao longo da cadeia como forma de fomentar sistemas de abastecimento sustentados por hábitos alimentares adequados às condições territoriais e ecológicas locais, como diversidade e sazonalidade, aliando segurança alimentar ao desenvolvimento rural local.

No Brasil, muito embora a expansão dos supermercados e o processo de fusões e aquisições de pequenos equipamentos e redes nacionais apontem para o enfraquecimento do sistema convencional de abastecimento, ainda resistem nas grandes e médias cidades um importante circuito de varejo alimentar sustentado nas feiras livres, mercados municipais e pequenos supermercados independentes, comércio familiar de pequena escala

\footnotetext{
In Barcelona, Making the Markets Fresh Again. New York Times, Edição de Outubro de 2015. Disponível em $<$ https://www.nytimes.com/2014/10/19/travel/in-barcelona-making-the-markets-fresh-again.html?_r =0>. Acesso em: 15 Abr. 2017

${ }^{\circ} \mathrm{O}$ termo foodshedf oi mencionado pela primeira vez em 1929, por W.P Hedden, com o trabalho HowGreatCities Fed. Sua análise aponta para o leque de questões relacionados ao sistema de distribuição da comida, incluindo o importante problema do desperdício, a necessidade de terminais municipais de alimentos, o custo de transporte para os consumidores e na época, o problema, hoje anacrônico, de ter-se apenas lojas muito pequenas para comercialização dos alimentos (POTHUKUCHI, KAUFMAN, 2000).

${ }^{10}$ Dos 72 food hubs pesquisados pela National Food Collaboration em 2011, 47\% afirmou que estava distribuindo ativamente produtos para locais de desertos alimentares, aumentando, assim, acesso a alimentos frescos e locais en áreas em que muito provar lmente não haveri esse tipo de oferta Além disso, nesmo em casos onle os food habs não atuan o no intuito de aumentar o acesso aos alimentos. Não por acaso um dos mais importantes trabalhos sobre Food Hubs foi intitulado "The MissingMidle", com o objetivo de frisar que o problema de abastecimento está no desapareci-
} mento do meio, da organização da intermediação (BARHAM, 2011).

operando como varejo de vizinhança.

Algumas das características do sistema tradicional são a pequena escala, alta ramificação, utilização do trabalho familiar, baixa capitalização, adaptação ao consumo pequeno e irregular, utilização da caderneta, entre outros elementos. Essa lógica de organização implica em elementos aqui considerados relevantes: a menor escala e distribuição espacial capilar no espaço urbano sugerem um arranjo que se contrasta com a padronização do acesso e dos produtos impulsionada pelas grandes redes. Ou seja, esse sistema sugere a possibilidade de maior diversidade de organização de suas cadeias de suprimentos, ou pelo menos um formato não verticalizado e centralizado e, simultaneamente, um arranjo de distribuição mais pulverizado ao longo do espaço urbano pela própria condição de menor escala.

Em geral, as feiras livres, especialmente pelo seu deslocamento espacial, bem como os pequenos mercados familiares, apresentam uma forma de resistência à tendência de formação de desertos alimentares provocados pela oligopolização do varejo. A capilaridade desse sistema, portanto, não remete apenas à sua distribuição espacial, mas a um arranjo que engloba formas complementares de comercialização: mercearias, varejões, feiras, mercadinhos, mercados municipais, etc. Em outras palavras, trata-se de um desenho heterogêneo que se opõe à lógica de expansão supermercados: o problema não se situa no grande autosserviço em si, mas na sua crescente dominância e as implicações disso sobre o perfil alimentar e sobre a estrutura produtiva na medida em que o mercado se concentra.

A menor escala dos equipamentos do sistema tradicional sugere, ainda, uma maior diversidade para trás da cadeia, ou seja, do sistema produtivo. Uma pergunta inversa também poderia ser feita aqui: que formatos de comercialização suportam ou são adequados à diversidade de produtos? O pressuposto aqui é de que a menor escala poderia significar canais diversificados de fornecimento e, portanto, uma menor padronização da alimentação da população e dos sistemas produtivos. Segundo a pesquisa GfK sobre mercados de vizinhança ${ }^{11}$, quase $90 \%$ desses equipamentos no Brasil são empresas familiares (ABRAS, 2015) e 79\% desse tipo de comércio, em 2011, eram lojas pequenas e independentes e não redes de supermercados locais (ABRAS, 2012).

Ou seja, esses equipamentos se contrapõem à lógica concentração e organização em larga escaladas grandes redes. Complementarmente e ainda

"Pequenos supermercados independentes com no máximo 4 checkouts. v. 20, n.2, $2017 \quad$ RETRATOS DE ASSENTAMENTOS 
segundo a pesquisa, esses equipamentos tendem a comercializar marcas locais ou regionais de produtos (ABRAS, 2013), o que não é diferente para os produtos in natura, comercializado por $70 \%$ desses equipamentos (ABRAS, 2015): em 2012, 35\% do mix de FLV ${ }^{12}$ provinha dos produtores sendo apenas $16 \%$ provenientes de centrais de abastecimento e, no mesmo ano, $43 \%$ do varejo de vizinhança comercializavam produtos orgânicos (ABRAS, 2013). Cabe, ainda, ressaltar que seu preço chegou, em média, a ser $8,6 \%$ mais barato comparativamente às grandes redes (ABRAS, 2014).

Assim como os pequenos supermercados familiares que resistiram ao domínio do varejo alcançados pelas grandes lojas das redes de autosserviço nas grandes e médias cidades brasileiras, as feiras livres e os mercados municipais sobrevivem. Como destaca Junqueira e Peetz (2015), a despeito dos seus críticos que insistem em apontarem as feiras como obsoletas e inconvenientes, o imaginário social segue atribuindo a esses equipamentos significados que desbordam as simples relações de compra e venda, levando frequentadores e aqueles que já não mais vão às feiras e mercados saírem em defesa daqueles espaços a cada vez que alguma autoridade tenta interferir no seu funcionamento ou existência.

Não por acaso, o varejo moderno tenta insistentemente recriar nos espaços assépticos e impessoais de suas lojas ou em shopping centers arranjos que remetem, na organização em barracas, no alinhamento e setorização dos produtos e até mesmo recriando versões gourmet de ícones de feiras e mercados tais como pastel, caldo de cana, sanduiches, na expectativa de capturar, pela associação de memórias, parte da clientela das feiras e mercados; desnecessário dizer sobre o malogro que acompanha tais tentativas. Novamente invocando (JUNQUEIRA; PEETZ, 2015) a feira é subversiva, é invasiva, pulsante de vida, de sons, afetos e encontros, requerimentos impossíveis aos frio e impessoal mundo da luz artificial e do ar condicionado.

A conjunção de supermercados familiares, sacolões e varejões, mercados municipais e feiras livres formam um sistema de varejo alimentar que nada na contracorrente da padronização e das grandes marcas. Em pesquisa

${ }^{12}$ Mix de FLV referência à composição da oferta (mix) de frutas, legumes e verduras (FLV) para a comercialização no varejo alimentar. A ideia de mix remete à possibilidade de arranjos de preços ponderados pelas elasticidades de demanda de cada item de sorte que seja possível compensar eventuais reduções de margen de um grupo de itens com a expansão das margens de outros, alcançando-se assim um padrão de preços adeuna d refla dos con quado à teda dos conn exclusivamente para equipamentos de pequena escala .Os arranjos semelhantes nas grandes redes são mui mais complexos e consideram variáveis extra - produtos tais como prazos de pagamentos, giro financeiro, etc. recente sobre o sistema convencional de abastecimento do Distrito federal, Leda (2017) observou que seu sistema tradicional de varejo de alimentos exibia uma oferta diversificada e produzidos localmente ou regionalmente, incluindo nesse rol, desde gêneros in natura a alimentos industrializados.

A pesquisadora identificou, também, a existência de um perfil diversificado e dinâmico de aquisição de produtos que se contrapunha ao modelo verticalizado e padronizado do moderno sistema de varejo, o que evidenciou a capacidade do arranjo convencional em estimular a agricultura e a agroindústria local, regional e de natureza familiar. Apesar da inexistência de dados confiáveis em razão da ausência de estudos e, quiçá, interesse do governo do Distrito Federal na temática dos sistemas convencionais de varejo, Leda (2017) constatou nas suas investigações a presença de expressivo conjunto de produtos industrializados de marcas locais e regionais além da presença na composição da oferta de gêneros in natura, da produção local de pequena escala, principais fornecedores do varejo tradicional.

Assim, a resistência do sistema convencional de varejo na forma de feiras livres, mercado municipais ou mesmo os mercadinhos familiares representa, a princípio, um instigante espaço de investigação quanto aos benefícios gerados seja pela proximidade entre a produção e o consumo, seja pela preservação de práticas e hábitos alimentares que a oferta diversificada e regionalizada de alimentos permite.

\section{Conclusões}

A questão alimentar urbana atual, no Brasil, tende repetir os contornos do que acontece no restante do mundo: oligopólio dominando a produção no campo, oligopólios controlando o processamento e industrialização de alimentos e oligopólios dominando quase que completamente o varejo por intermédio das grandes redes de supermercados e autosserviço.

Esse cenário ganha contornos mais preocupantes na medida em que $o$ domínio exercido sobre toda a cadeia alimentar, da produção ao consumo, pelas grandes corporações subverteu a noção de comida deslocando para muito distante das possibilidades da população em geral pela via do preço, $\mathrm{o}$ acesso a uma dieta saudável e segura. As consequências já se fazem notar quando a Pesquisa Nacional por Amostra Domiciliar (PNAD) e a VIGITEL, do Ministério da Saúde, revelam o avanço do excesso de peso que atinge quase $60 \%$ dos brasileiros e a escalada vertiginosa das Doenças Crônicas 
não Transmissíveis, como hipertensão, diabetes, agravos coronarianos, do trato hepático, dentre outras. Na identificação das causas desses males todos, sobressai a dieta assentada no consumo excessivo de produtos ricos em gorduras, açúcares e sódio e miseráveis em fibras e nutrientes. A porta de entrada dessa dieta, os supermercados, equipamento preferencial de compras da população.

Novamente, são os mais pobres os mais atingidos pelo consumo inadequado desses alimentos. A assimetria entre a renda disponível e os preços do que se entende como alimentos seguros e saudáveis recria em pleno século XXI o paradoxo clássico do abastecimento onde os mais ricos gastam menos para comerem melhor.

Na contracorrente dessa tendência, resiste o sistema tradicional de varejo alimentar assentado nos pequenos mercados familiares de vizinhança, nas feiras livres e mercados municipais que, pelo menos nas grandes e médias cidades onde conseguiram sobreviver, têm atendido a cada dia um número crescente de consumidores.

A resistência tem se dado tanto por conta da força das práticas e hábitos alimentares das populações viventes nas áreas de influência desses equipamentos quanto em razão dos impactos da compressão do espaço - tempo que tem tornado o cotidiano do citadino uma luta permanente contra o tempo e as demandas privadas deslocadas pelas obrigações do emprego, do trabalho. Com tempos cada dia mais comprimidos em razão das dificuldades de mobilidade, a loja de vizinhança volta para a agenda de prioridades levando esses equipamentos a experimentarem um novo período de vitalidade e diversificação das suas ofertas.

As pesquisas da GfK sobre o pequeno varejo e a resistência das feiras livres e mercados - apenas de quando em quando objeto de algum estudo ou pesquisa -, evidenciam a importância desse tipo de comércio para a manutenção e melhoria das condições de participação de fornecedores de baixa escala - agricultores familiares, pequenas indústrias locais e regionais. São esses fornecedores, praticantes de uma agricultura diversificada, ou a pequena indústria de transformação que processa produtos alimentícios tradicionais os responsáveis pela melhoria das oportunidades de acesso a uma alimentação saudável e segura ao alcance da população em geral.

Assim, ao reivindicarmos a atenção para o sistema tradicional de abastecimento alimentar urbano, marcamos nossa posição em defesa de uma agricultura diversificada e segura, uma ideia de comida que preserve as raízes na história da nossa sociedade. Em outros termos, esse ensaio buscou chamar a atenção dos que se interessam pelo tema da alimentação, quanto a importância do Estado voltar a se responsabilizar pelas condições que propiciem a plena fruição do Direito Humano à Alimentação no Brasil.

\section{Referências}

ABRAS e GfK, Revista SuperHiper, Edição de Junho de 2012. Disponível em: <http://abrasnet.com.br/edicoesanteriores/Main. php?MagID=7\&MagNo=87>. Acesso em: 28 Dez. 2016

ABRAS e GfK, Revista SuperHiper,Edição de Junho de 2013. Disponível em: <http://abrasnet.com.br/edicoes-anteriores/Main. php?MagID=7\&MagNo=104>. Acesso em: 28 Dez. 2016

ABRAS e GfK, Revista SuperHiper,Edição de Junho de 2014. Disponível em: <http://abrasnet.com.br/edicoes-anteriores/Main. php?MagID=7\&MagNo=134>. Acesso em: 28 Dez. 2016

ABRAS e GfK, Revista SuperHiper,Edição de Junho de 2015. Disponível em: <http://abrasnet.com.br/edicoes-anteriores/Main. php?MagID=7\&MagNo=158>. Acesso em: 28 Dez. 2016

ABRAS, 29 de Março de 2016. Disponível em: < http://www.abrasnet.com. br/clipping.php?area=20\&clipping=55616> . Acesso em: 28 Dez. 2016.

ABRAS/Revista SuperHiper. Associação Brasileira de Supermercados, Revista SUPERHIPER, edição de abril, 2014. Disponível em: <http:// abrasnet.com.br/edicoes-anteriores/Main.php?MagID=7\&MagNo=129>. Acesso em: 28 Dez. 2016

BARHAM, James. Regional Food Hubs: Understanding the scope and scale of food hub operations. Washington, DC: USDA AMS, 2011.

BEAULAC, Julie; KRISTJANSSON, Elizabeth; CUMMINS, Steven. A systematic review of food deserts, 1966-2007. Prev Chronic Dis, v. 6, n. 
3, p. A105, 2009.

BELIK, Walter. Muito além da porteira. Série Teses. Instituo de Economia da Unicamp, 2001.

BELIK, Walter; CHAIM, Nuria Abrahão. Formas híbridas de coordenação na distribuição de frutas, legumes e verduras no Brasil. Revista Cadernos de debate, v. 7, p. 1-9, 1999.

BELIK, Walter; CUNHA, Altivo Roberto Andrade de Almeida. A produção agrícola e a atuação das Centrais de Abastecimento no Brasil. Segurança Alimentar e Nutricional, v. 19, n. 1, p. 46-59, 2012.

COCKRALL-KING, Jennifer. Food and the city: urban agriculture and the new food revolution. Estados Unidos, Prometheus Books, 2012, 372 p.

CUMMINS, Steven. Food deserts. The Wiley Blackwell Encyclopedia of Health, Illness, Behavior, and Society, 2014.

DA SILVA, José Francisco Graziano. A modernização dolorosa: estrutura agrária, fronteira agrícola e trabalhadores rurais no Brasil. Zahar Editores, 1982.

DE MELLO, João Manuel Cardoso. O capitalismo tardio: contribuição à revisão crítica da formação e do desenvolvimento da economia brasileira. Editora Brasiliense, 1982.

DIOP, Ndiame; JAFFEE, S. Fruits and vegetables: global trade and competition in fresh and processed product markets. Global agricultural trade and developing countries, p. 237-257, 2005.

IBGE (Instituto Brasileiro de Geografia e Estatística Disponível), Estatísticas do Século XX, 2007. Disponível em: http://seculoxx.ibge.gov.br/

IBGE. Instituto Brasileiro de Geografia e Estatística Disponível. Cidades. Disponível em: <http://cidades.ibge.gov.br/xtras/perfil. php?codmun=530010> Acesso em: 20 Dez. 2016.
INSTITUTO BRASILEIRO DE GEOGRAFIA E ESTATÍSTICA. Pesquisa Nacional por Amostra de Domicílios - PNAD, 2013.

INSTITUTO BRASILEIRO DE GEOGRAFIA E ESTATÍSTICA. Pesquisa de Orçamentos Familiares 2008-2009: antropometria e estado nutricional de crianças, adolescentes e adultos no Brasil. IBGE, 2010.

JUNQUEIRA, Antonio Hélio; PEETZ, Marcia da Silva. 100 anos de feiras livres na cidade de São Paulo; tradução Traduzca.com; fotografias Maycon Lima; Jailton Leal. São Paulo: Via Impressa Edições de Arte, 2015. 312 p.

LANG, Tim. Reshaping the food system for ecological public health. Journal of Hunger \& Environmental Nutrition, v. 4, n. 3-4, p. 315-335, 2009.

LEDA, Luisa Corrêa. Sistema tradicional de varejo de alimento e sua importância para a segurança alimentar e nutricional: o caso do Distrito Federal. 2011, 133 f. Dissertação (Mestrado em Meio Ambiente e Desenvolvimento Rural) - Universidade de Brasília, Brasília, 2017.

MORGAN, Kevin. Feeding the city: The challenge of urban food planning. International Planning Studies, p.341-348, 2009.

MÜLLER, Geraldo. Fome: o não-direito do não-cidadão. Covre, MLM A cidadania que não temos. São Paulo, Brasiliense, p. 13-38, 1986.

PAIVA, Ruy Miller. Reflexões sôbre as tendências da produção, da produtividade e dos preços do setor agrícola do brasil.". Revista Brasileira de Economia, junho, 1966.

PAN AMERICAN HEALTH ORGANIZATION, WORLD HEALTH ORGANIZATION. Consumption of ultra-processed food and drink products in Latin America: Trends, impact on obesity, and policy implications. 2014.

POTHUKUCHI, Kameshwari; KAUFMAN, Jerome L. The food system: A stranger to the planning field. Journal of the American planning association, v. 66, n. 2, p. 113-124, 2000. 
PRITCHARD, Bill. Regoverning Markets: A Place for Small-Scale Producers in Modern Agrifood Chains? Journal of Agrarian Change, v. 9, n. 3, p. 449-452, 2009.

REARDON, Thomas; BERDEGUE, Julio A. The rapid rise of supermarkets in Latin America: challenges and opportunities for development. Development policy review, v. 20, n. 4, p. 371-388, 2002.

REARDON, Thomas; BERDEGUÉ, Julio A. The retail-led transformation of agrifood systems and its implications for development policies. Latin American Center for Rural Development (RIMISP), Santiago, Chile, 2006.

SILVEIRA, Maria Laura; SANTOS, Milton. O Brasil: território e sociedade no início do século XXI. Rio de Janeiro: Record, 2001.

STEEL, Carolyn. Hungry city: How food shapes our lives. Random House, 2013.

SUPERMERCADO MODERNO, Relatório Anual, ano 41, nº 4, 2010. The Food Trust. Philadelphia Healthy Corner Store Network, Philadelphia Department of Public Health, 2014.

WISKERKE, Johannes SC. On places lost and places regained: Reflections on the alternative food geography and sustainable regional development. International planning studies, v. 14, n. 4, p. 369-387, 2009.

\section{SISTEMA NACIONAL DE SEGURANÇA ALIMENTAR E NUTRICIONAL NA DINÂMICA DE ESTADO: ABRANGÊNCIA E LIMITES DA POLÍTICA SOCIAL}

Raimundo Pires Silva Helena Carvalho De Lorenzo

Resumo: Por que as políticas sociais de Segurança Alimentar e Nutricional, enquanto uma ação de Estado de garantia de direitos e dever do Estado, não consolidaram a plenitude dos seus objetivos? O presente artigo busca apontar alguns aspectos relacionados ao fato de que, mesmo exitosas, essas políticas sociais estabelecidas pelo arcabouço do Sistema Nacional de Segurança Alimentar e Nutricional (SISAN), implantadas pelo governo democrático, de cunho centro-esquerda do presidente Lula, e continuadas pelo governo sucessor da presidenta Dilma, não concluíram os objetivos da estratégia Fome Zero.

Palavras-chave: Estado; Políticas Públicas; Segurança Alimentar.

Abstract: Why the social policies of Food and Nutrition Security, as a State action guaranteeing the rights and duty of the State, did not consolidate with fullness its objectives? This article seeks to point out some aspects related to the fact that, even if successful, these social policies established by the framework of the National System of Food and Nutrition Security (SISAN), implemented by the democratic government, center-left of President Lula, and continued by the successor government of President Dilma, did not complete your objectives of the Zero Hunger strategy.

Keywords: State; Public policy; Food Nutrition. 